\title{
NKT cells as an ideal anti-tumor immunotherapeutic
}

\section{Shin-ichiro Fujii ${ }^{1}$, Kanako Shimizu ${ }^{1}$, Yoshitaka Okamoto ${ }^{2}$, Naoki Kunii $^{2}$, Toshinori Nakayama ${ }^{3}$, Shinichiro Motohashi ${ }^{4}$ and Masaru Taniguchi ${ }^{5}$ *}

1 Laboratory for Immunotherapy, RCAI, RIKEN, Center for Integrative Medical Sciences (IMS-RCAl), Yokohama, Japan

${ }^{2}$ Department of Otorhinolaryngology, Graduate School of Medicine, Chiba University, Chiba, Japan

${ }^{3}$ Department of Immunology, Graduate School of Medicine, Chiba University, Chiba, Japan

${ }^{4}$ Department of Medical Immunology, Graduate School of Medicine, Chiba University, Chiba, Japan

${ }^{5}$ Laboratory of Immune Regulation, RCAI, RIKEN, Center for Integrative Medical Sciences (IMS-RCAI), Yokohama, Japan

\section{Edited by:}

Kendall A. Smith, Cornell University, USA

\section{Reviewed by:}

Kendall A. Smith, Cornell University, USA

Wolf Hervé Fridman, University Paris Descartes, France

\section{${ }^{*}$ Correspondence:}

Masaru Taniguchi, Laboratory of Immune Regulation, RCAI, RIKEN, Center for Integrative Medical Sciences (IMS-RCAI), 1-7-22 Suehiro-cho, Tsurumi-ku, Yokohama, Kanagawa 230-0045, Japan e-mail: taniguti@rcai.riken.jp
Human natural killer T (NKT) cells are characterized by their expression of an invariant $T$ cell antigen receptor $\alpha$ chain variable region encoded by a $V_{\alpha} 24 \mathrm{~J} \alpha 18$ rearrangement. These NKT cells recognize $\alpha$-galactosylceramide ( $\alpha$-GalCer) in conjunction with the MHC class I-like CD1d molecule and bridge the innate and acquired immune systems to mediate efficient and augmented immune responses. A prime example of one such function is adjuvant activity: NKT cells augment anti-tumor responses because they can rapidly produce large amounts of IFN- $\gamma$, which acts on NK cells to eliminate MHC negative tumors and also on CD8 cytotoxic T cells to kill MHC positive tumors. Thus, upon administration of $\alpha$-GalCerpulsed DCs, both MHC negative and positive tumor cells can be effectively eliminated, resulting in complete tumor eradication without tumor recurrence. Clinical trials have been completed in a cohort of 17 patients with advanced non-small cell lung cancers and 10 cases of head and neck tumors. Sixty percent of advanced lung cancer patients with high IFN- $\gamma$ production had significantly prolonged median survival times of 29.3 months with only the primary treatment. In the case of head and neck tumors, 10 patients who completed the trial all had stable disease or partial responses 5 weeks after the combination therapy of $\alpha$-GalCer-DCs and activated NKT cells. We now focus on two potential powerful treatment options for the future. One is to establish artificial adjuvant vector cells containing tumor mRNA and $\alpha-G a l C e r / C D 1 d$. This stimulates host NKT cells followed by DC maturation and NK cell activation but also induces tumor-specific long-term memory CD8 killer T cell responses, suppressing tumor metastasis even 1 year after the initial single injection. The other approach is to establish induced pluripotent stem (iPS) cells that can generate unlimited numbers of NKT cells with adjuvant activity. Such iPS-derived NKT cells produce IFN- $\gamma$ in vitro and in vivo upon stimulation with $\alpha-\mathrm{GalCer} / \mathrm{DCs}$, and mediated adjuvant effects, suppressing tumor growth in vivo.

Keywords: NKT cells, adjuvant effects, clinical trial, induced pluripotent stem cells, artificial adjuvant vector cells

\section{DISCOVERY OF NKT CELLS EXPRESSING AN INVARIANT V $\alpha 14 J \propto 18$ ANTIGEN RECEPTOR}

Natural killer T (NKT) cells are characterized by the expression of an invariant antigen receptor encoded by V $\alpha 14 \mathrm{~J} \alpha 18$ in mice and $\mathrm{V} \alpha 24 \mathrm{~J} \alpha 18$ in humans (1-3). The murine invariant $\mathrm{V} \alpha 14 \mathrm{~J} \alpha 18$ NKT cell antigen receptor was identified by cloning of cDNAs encoding $\mathrm{T}$ cell antigen receptor (TCR) from 13 independently established hybridomas with regulatory functions $(4,5)$. Surprisingly at that time, Southern blot analysis of TCR usage by these 13 hybridomas had the same DNA restriction fragment length polymorphism (RFLP) patterns, even when three different enzymes, EcoRI, BamHI, and HindIII were used. Because of this unusual homogeneous DNA restriction pattern, the TCR cDNAs were cloned and could be classified into four types at the nucleotide level, all of which were composed of V $\alpha 14$ and $J \alpha 18$ with a 1-nt $\mathrm{N}$ region. The $\mathrm{N}$ region was different in each clone, a C, A, T, or G nucleotide. However, any nucleotide addition in the $\mathrm{N}$ region at this position becomes invariant at the amino acid level, because this $\mathrm{N}$ region is the third base of a glycine codon (5).

By RNase protection assays using antisense $V \alpha 14 \mathrm{~J} \alpha 18$ of C57BL/6 (B6) origin as a probe, we detected a single $630 \mathrm{bp}$ band in B6, a single $400 \mathrm{bp}$ band in BALB/c, and 630/400 double bands in DBA/2 mice. Quite remarkably, this band(s) represented $2-4 \%$ in the total TCR $\alpha$ expression in these mice (6). The theoretical expression frequency of any one particular TCR $\alpha$ is calculated to be $1 / 10^{6}$, because the total TCR $\alpha$ chain repertoire is around $10^{8}$ and there are $100 \mathrm{~V} \alpha$ segments in the TCR $\alpha$ loci. Therefore, the $\mathrm{V} \alpha 14 \mathrm{~J} \alpha 18$ expression frequency detected in unprimed mice was more than $10^{4}$ times higher than expected, suggesting that $\mathrm{V} \alpha 14^{+}$ NKT cells are clonally expanded under physiological conditions, likely do to their intrinsic autoreactivity. Another interesting finding was that the invariant $\mathrm{V} \alpha 14 \mathrm{~J} \alpha 18$ receptor is used only by NKT cells and not by conventional $\alpha \beta$ T cells. This was shown conclusively when the invariant $\mathrm{V} \alpha 14 \mathrm{~J} \alpha 18$ together with TCRV $\beta 8.2$ was introduced into RAG-knockout (KO) mice; only NKT cells and 
not conventional $\alpha \beta$ T cells or NK cells developed (7). These and other studies confirmed that expression of $\mathrm{V} \alpha 14 \mathrm{~J} \alpha 18$ in mice and $\mathrm{V} \alpha 24 \mathrm{~J} \alpha 18$ in human is a unique NKT cell signature.

\section{DISCOVERY OF THE NKT CELL LIGAND}

The ligand for NKT cells was identified as $\alpha$-galactosylceramide ( $\alpha$-GalCer), which is presented by the MHC class I-like CD1d molecule. However, unlike MHC class I molecule with polymorphic in nature, CD1d is monomorphic among species, indicating that $\alpha$-GalCer can be used in any potential NKT cell therapy for all humans. The glycolipid nature of the NKT cell ligand was suggested by experiments using mice lacking the transporter associated with antigen processing (TAP), which is essential for translocation of cytoplasmic peptides generated by the ubiquitinproteasome proteolytic pathway into the endoplasmic reticulum (ER) to make a stable complex with MHC class I molecules. The MHC peptide complex is required to select CD8 T cells, therefore, in TAP-KO mice, CD8 T cells are not generated. However, by RNase protection assays using the invariant $\mathrm{V} \alpha 14 \mathrm{~J} \alpha 18$ as a probe, we could detect significant levels of protected bands in TAP-KO mice but not in $\beta 2 \mathrm{M}-\mathrm{KO}$ mice, suggesting that the ligand is not a peptide, but likely to be a glycolipid in conjunction with a $\beta 2 \mathrm{M}$-associated MHC-like molecule (8). The MHC-like molecule turned out to be CD1d, which has two large hydrophobic pockets, $\mathrm{A}^{\prime}$ and $\mathrm{F}^{\prime}$, that can bind the two long fatty acid chains of the ceramide portion of $\alpha$-GalCer (9). Therefore, we screened various synthetic glycolipids and found the essential structurefunction relationships critical for the NKT cell recognition, such as: (1) $\alpha$-linkage between the sugar moiety and the ceramide portion of $\alpha$-GalCer but not $\beta$-GalCer, (2) a $2^{\prime}-\mathrm{OH}$ configuration on the sugar moiety different from $\alpha$-ManCer, and (3) a $3^{\prime}-\mathrm{OH}$ on the sphingosine of $\alpha$-GalCer (10).

Furthermore, by using alanine substitution to mutagenize CD1d, we also identified important amino acids on CD1d, such as Ser76, Arg79, Asp80, Glu83, and Gln153, for activation of NKT cells in mice (11). In 2007, Borg et al. succeeded in crystallizing the triple complex of $\alpha$-GalCer/human V $\alpha 24$ J $\alpha 18 / T C R V \beta 11 /$ human CD1d (12). Interestingly, the $\mathrm{V} \alpha 24 \mathrm{~J} \alpha 18$ chain docks in parallel with the CD1d cleft without any direct contribution of the TCR $\beta$ chain to ligand binding. This configuration is quite different from the mode of ligand recognition by the TCR $\beta$ chain of conventional $\alpha \beta$ T cells, in which only the TCR $\beta$ but not the TCR $\alpha$ chain recognizes the $\mathrm{MHC}$ bound peptide in a diagonal position.

Analysis of the structure also revealed that the first four amino acids (Asp94, Arg95, Gly96, and Ser97) of Ja18, which are conserved in mouse and human, are essential for binding with both CD1d and $\alpha$-GalCer. The J $\alpha 18$ Asp94 binds with CD1dArg79, Ja18Arg95 with CD1dArg79/Ser76/Asp80 and the $3^{\prime}$ $\mathrm{OH}$ on the sphingosine, J $\alpha 18 \mathrm{Gly} 96$ with the $2^{\prime}-\mathrm{OH}$ on galactose, and $\mathrm{J} \alpha 18$ Ser97 with CD1dGln150. Interestingly, the CD1d amino acid, Glu83, defined as important in functional assays with CD1d mutants, is important for binding with the TCR $\beta$ chain to make a stable complex with CD1d but has no direct contribution to the ligand binding itself. Moreover, the CD1d amino acids (Ser76, Arg79, and Asp80) important for binding with either $\alpha$-GalCer or J $\alpha 18$ are also well conserved among species such as mouse, rat, sheep, and human (10, 13-15). Thus, $\alpha$-GalCer, identified as an NKT cell ligand in mice can also be used to activate human NKT cells.

\section{NKT CELL-MEDIATED ADJUVANT EFFECTS ON INNATE AND ADAPTIVE IMMUNITY AGAINST CANCER}

In general, tumor cells do not contain any adjuvant materials, so that it is difficult to induce proliferation of specific $\mathrm{T}$ cell clones to mount anti-tumor responses in patients. On this particular point, $\alpha$-GalCer overcomes these problems by its intrinsic adjuvant activity, inducing clonal expansion of tumor-specific $\mathrm{T}$ cell cells as well as activating various innate cell types (16). In the initial anti-tumor response after stimulation with $\alpha$-GalCer/DCs, NKT cells immediately produce large amounts of IFN- $\gamma$, which acts on DCs, NK cells, and neutrophils in the innate immune system to eliminate MHC negative tumor target cells and, at the same, also on CD8 cytotoxic T cells and CD4 Th1 cells to kill MHC positive tumor cells, resulting in tumor eradication (Figure 1) $(1,17,18)$. Therefore, NKT cell-targeted therapy is expected to overcome the major problem of current anti-cancer immunotherapies - recurrent tumors - due to their targeting of only one type of effector cell $(10,19,20)$. For example, in the immunotherapy using tumor peptide CTL or antibodies against PD-1 or CTLA4, the target is the CD8 killer T cell, which kills MHC positive but not negative tumor cells, resulting in tumor recurrence (21). Similarly, in the artificial cells recently developed by the forced expression of Rae1/H60 (NKG2D-L), Mult-1 (NKG2D-L), or CD70 (TNF-L), the target cells are NK cells, which will eliminate MHC negative, but not MHC positive tumor cells (22).

Tumors in general contain both MHC positive and negative cells. Therefore, for an optimal therapy, both MHC types of tumor cells should be eliminated simultaneously by activating both innate and adaptive immune responses (Figure 1A). Since only NKT cells, but not other immune cells, activate NK and CD8 killer T cells at the same time, thus eliminating both MHC positive and negative tumor cells, the NKT cell-targeted therapy is a promising strategy for cancer treatment (Figures 1B,C).

\section{NKT CELL-MEDIATED ADJUVANT EFFECTS ON DC MATURATION}

Another important NKT cell function is their ability to interact with immature DCs in the presence of $\alpha$-GalCer to induce DC maturation (17). Therefore, NKT cell-targeted therapy is also useful for advanced cancer patients, who often suffer from severe immunodeficiency. DCs in these advanced cancer patients are usually immature because of the presence of immune suppressive cytokines, such as IL-10 or TGF $\beta$, produced by tumor cells (Figure 1A) (23). The immature DCs are able to capture tumor antigens, but unable to activate specific T cells. However, immature DCs presenting $\alpha$-GalCer are activated by NKT cells through CD40-CD40L interactions to produce IFN- $\gamma$, which induce full DC maturation (24). This leads to a robust interleukin (IL)-12 response to further activate NKT cells, followed by activation of CD8T cells and NK cells $(17,24)$.

The DC maturation by activated NKT cells is a prominent strategy for the enhancement of protective innate and acquired immune responses. To investigate the mechanisms of bystander potential of $\alpha$-GalCer-activated NKT cells, an experimental system 


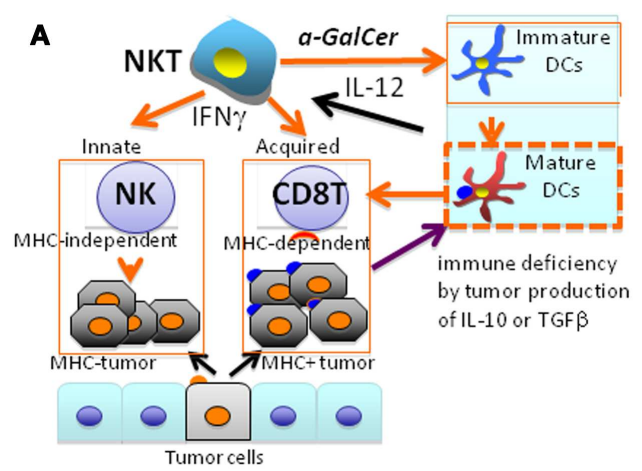

C

\begin{tabular}{|c|c|c|}
\hline & Case & Results \\
\hline Pharyngeal $\mathrm{Ca}$ & 001 & $\mathrm{SD}\left(87^{\circ} \%\right)$ \\
\hline Maxillary Ca & 002 & $\mathrm{SD}(97 \%)$ \\
\hline Maxillary $\mathrm{Ca}$ & 003 & $\operatorname{PR}\left(63^{\circ} \%\right)$ \\
\hline Esophageal $\mathrm{Ca}$ & 004 & PR(68\%) \\
\hline Pharyngeal $\mathrm{Ca}$ & 005 & $\mathrm{PR}(58 \%)$ \\
\hline Pharyngeal $\mathrm{Ca}$ & 006 & $S D\left(96^{\circ} \%\right)$ \\
\hline Oral Ca & 007 & $\operatorname{PR}(67 \%)$ \\
\hline Laryngeal Ca & 008 & $\operatorname{SD}(74 \%)$ \\
\hline Laryngeal Ca & 009 & PR(65\%) \\
\hline Maxillary Ca & 010 & SD $(87 \%)$ \\
\hline
\end{tabular}

FIGURE 1 | Natural killer T cell-mediated adjuvant effects on anti-tumor protective responses and clinical trial outcomes. (A) Mechanisms of NKT cell-targeted adjuvant cell therapy: upon NKT cell activation in patients by $\alpha$-GalCer/DCs, immature DC become mature, and both MHC positive and negative tumor cells will be killed by CD8 killer T cells and NK cells, respectively. (B) Clinical trials of NKT cell-targeted adjuvant cell therapy on advanced non-small lung cancer: $60 \%$ of patients $\left({ }^{* *}\right)$ showed significant prolonged median survival time of 29.3 months compared with best

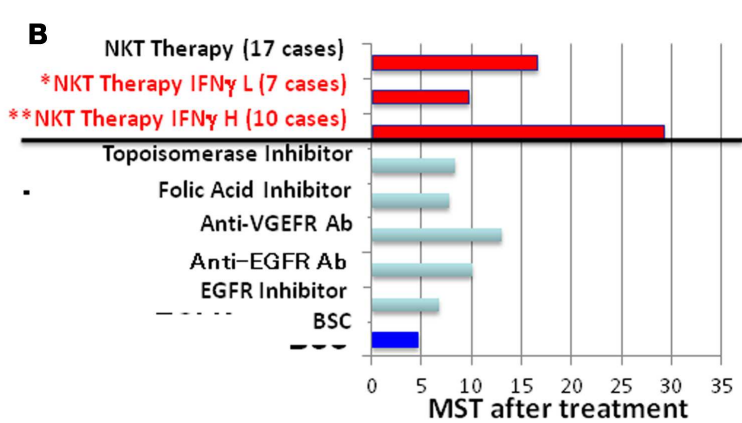

D

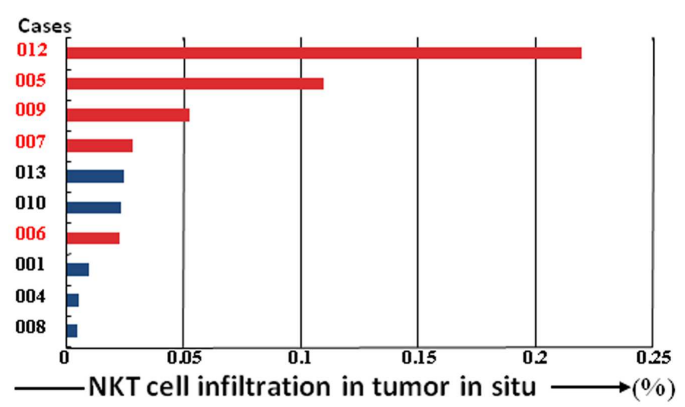

Fig. 1

supportive care group with a MST of 4.6 months. The response to NKT cell therapy correlated with clinical efficacy (median survival time) and IFN- $\gamma$ levels; patients with high $(* * \mathrm{H})$ levels responded significantly better than those with low $\left({ }^{*}\right.$ L) levels. (C) Clinical trials of NKT cell-targeted adjuvant cell therapy for head and neck tumors: all 10 cases treated with the combination therapy of $\alpha-G a l C e r / D C s$ and activated NKT cells showed significant clinical efficacy (SD or PR). (D) Correlation between clinical efficacy (PR in red, SD in black) of head and neck tumors and NKT cell numbers in the tumor in situ. using immunization with OVA-loaded TAP-deficient spleen cells loaded with OVA after permeabilization by osmotic shock was developed. In this system, OVA was used as an artificial tumor antigen to induce OVA-specific CD8 $\mathrm{T}$ cells to kill OVA-bearing tumor cells. Only after $\alpha$-GalCer administration, IFN- $\gamma$ production by $\mathrm{NK}$ and CD8T cells was observed (see Figure 2A). Under these conditions, the clonal expansion of OVAspecific CD8 $\mathrm{T}$ cells and strong anti-tumor responses develop in the mice, and the response requires co-administration of $\alpha$-GalCer (17).

\section{CLINICAL TRIAL OF NKT CELL-TARGETED THERAPY FOR ADVANCED LUNG CANCER AND HEAD AND NECK TUMORS}

For effective NKT cell activation, $\alpha$-GalCer/DC has distinct advantages to induce significant expansion of NKT cells and to inhibit in vivo tumor growth in a mouse model of metastatic lung cancer and liver metastasis in melanoma $(25,26)$. In a preclinical study, we used mouse melanoma cells, which were injected into the spleen to induce liver metastasis. Treatment of tumor-bearing mice by intravenous administration of $\alpha$-GalCer/DCs $\left(3 \times 10^{6}\right)$ resulted in complete eradication of the liver metastasis within 7 days after treatment (27).
Based on the dramatic effects of $\alpha$-GalCer/DCs in the preclinical studies, a clinical trial of NKT cell-targeted immunotherapy was conducted at Chiba University hospital in patients with advanced non-small cell lung cancer to evaluate the safety, feasibility, immunological responses, and clinical outcomes (28). Seventeen patients with advanced or recurrent non-small cell lung cancer refractory to the standard treatments, including surgery, chemotherapy, and radiation therapy, completed the protocol. The patient's peripheral blood mononuclear cells (PBMCs) obtained by apheresis were cultured with GMP grade GM-CSF and IL-2 for 7 days and then pulsed with $\alpha$-GalCer (29). The $\alpha$-GalCer-pulsed PBMCs were then intravenously administered $\left(1 \times 10^{9}\right.$ cells $/ \mathrm{m}^{2} /$ injection $)$ back into autologous patients twice with a 1-week interval followed by two courses with a 1-month interval between the second and third administration.

In the 17 patients who completed the protocol of a phase IIa clinical trial, the treatment was well-tolerated, and no severe adverse events related to the cell therapy were observed $(28,30)$. To monitor IFN- $\gamma$ production by NKT cells from the patients, an enzyme-linked immunospot (ELISPOT) assay was performed (31). The results demonstrated that a significant increase in the number of IFN- $\gamma$-producing PBMCs was detected in 10 out of 


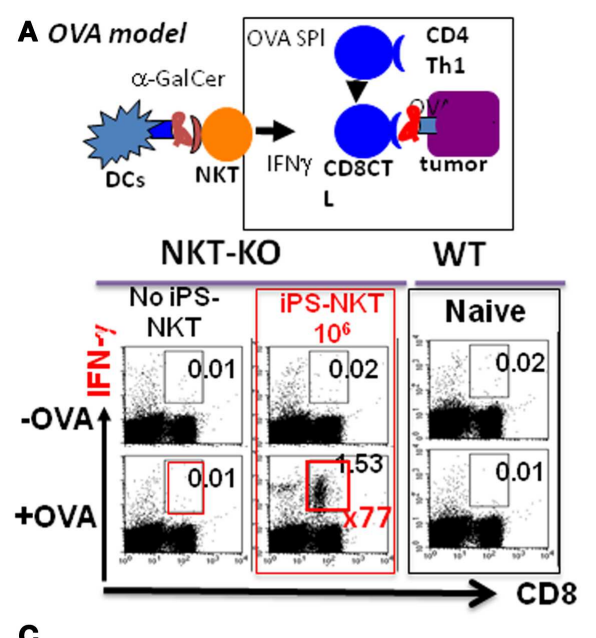

D
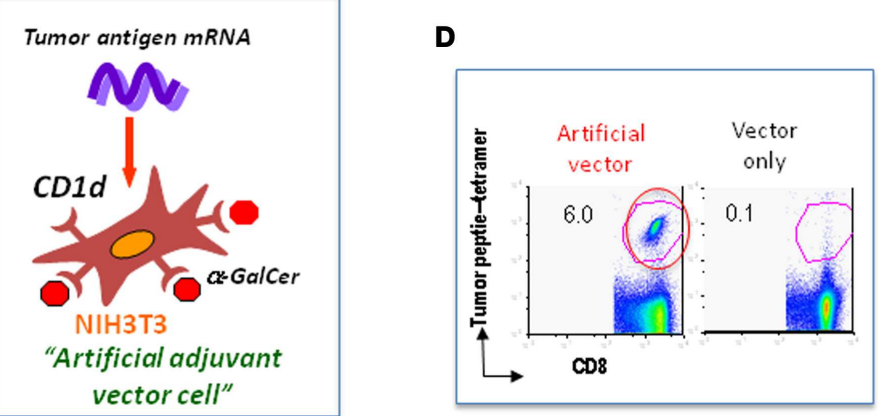

B

OVA-EL4 (EG7)

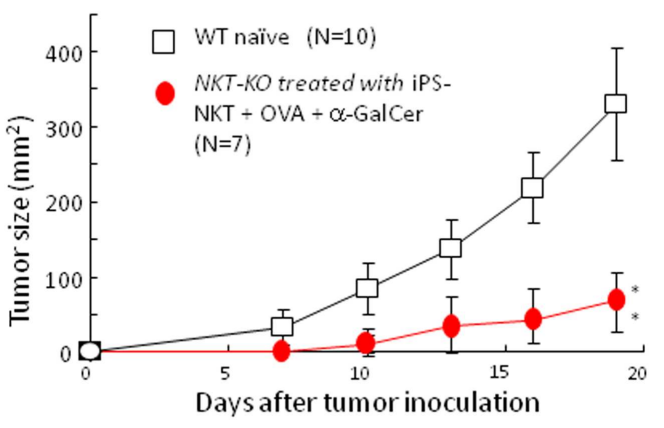

E

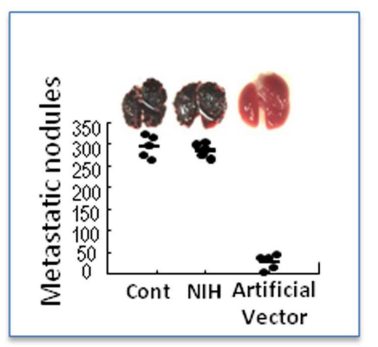

FIGURE 2 | Future directions for NKT cell-mediated cancer therapy. (A) Experimental model using OVA as an artificial tumor antigen to demonstrate NKT cell-mediated adjuvant activity (OVA model): the NKT-KO mice that had received iPS-derived NKT cells were immunized with OVA-loaded TAP-deficient spleen cells permeabilized by osmotic shock. A week later, the CD8 killer T cells in these immunized mice were analyzed for IFN- $\gamma$ production after restimulation with OVA antigen in vitro. A significant increase in the number of antigen-specific IFN- $\gamma$ producing CD8 killer T cells was detected in mice transferred with iPS-derived NKT cells. (B) Inhibition of the growth of OVA-expressing EL4 (EG7) tumor cells by NKT cell-mediated adjuvant therapy using iPS-derived NKT cells in vivo in the OVA model. A significant suppression of tumor growth in vivo was detected. (C) Generation of allogeneic artificial adjuvant vector cells. Artificial adjuvant vector cells were loaded with $\alpha$-GalCer/CD1d and transfected with tumor mRNA. (D) Detection of long-term memory antigen-specific CD8 killer T cells even 1 year after a single injection of artificial adjuvant vector cells. Antigen-specific CD8T cell responses in mice immunized with artificial adjuvant vector cells were analyzed using tetramer staining 1 year later. OVA was used in these experiments. (E) Suppression of melanoma lung metastasis after treatment with artificial adjuvant vector cells. Mice were intravenously injected with B16 melanoma cells to induce lung metastasis and, then $3 \mathrm{~h}$ later, intravenously with artificial adjuvant vector cells without tumor mRNA. The formation of metastatic nodules analyzed 2 weeks after melanoma cell injection was significantly suppressed according to the mechanisms of the activation of both NKT and NK cells but not that of CD8 killer T cells induced by artificial adjuvant vector cells carrying only $\alpha-G a l C e r / C D 1 d$ without tumor mRNA.
17 patients, which was correlated with a significantly prolonged median survival time (MST; 29.3 months) in comparison with the group with no increase compared to the pretreatment status in IFN- $\gamma$-producing cells (MST of 9.7 months) (Figure 1B) (32). The $\alpha$-GalCer-reactive IFN- $\gamma$ spot forming cells appeared to include both NKT cells and NK cells $(31,33)$, consistent with the notion that $\alpha$-GalCer-activated NKT cells subsequently stimulate NK cells to produce IFN- $\gamma(34,35)$. We also investigated NKT cell infiltration in the surgically resected tumor samples and found a significant increase (25- to 60 -fold) in the number of NKT cells in the tumor in situ (36). Because of the clinical correlation between increased IFN- $\gamma$ production and prolonged overall survival, we conclude that IFN- $\gamma$ may be a good biological marker for predicting clinical efficacy of this treatment. Although this prediction cannot be made prior to $\alpha$-GalCer/DCs administration, the monitoring of IFN- $\gamma$ production would still be valuable for patients receiving this immunotherapy. Although none of the cases showed significant tumor regression, the overall MST of all 17 patients (18.6 months) was superior to that of patients with best supportive care (4.6 months) or those treated with other types of therapies (average 10 months) in Figure 1B (37-40).

In the case of the head and neck tumors, we used a combination therapy with $\alpha$-GalCer/DCs $\left(10^{8}\right)$ and activated NKT cells $\left(5 \times 10^{7}\right)$ and completed 10 cases, including patients with pharyngeal, laryngeal, esophageal, maxillary, and oral carcinomas, who had advanced or recurrent disease after standard treatments (41). All treated patients showed either a partial response or achieved a stable disease state, indicating significant clinical efficacy (Figure 1C), which was associated with significant NKT cell infiltration into the tumor in situ (Figure 1D). To evaluate 
clinical efficacy, a computed tomography (CT) scan was performed a few days before enrollment and also after the treatment. In some cases with partial responses, we observed that the enhanced area decreased in size, and necrosis appeared at the center of the tumor.

These encouraging clinical studies on advance lung cancers and head and neck tumors warrant further evaluation of NKT cell-targeted immunotherapy for survival benefit. In general, the immunotherapy may be more effective in patients with low tumor burden. Currently, we have been conducting $\alpha$-GalCer/DC therapy for stage IIA to IIIA lung cancer patients with small tumor foci, including remaining micro-metastasis after radical surgery or after receiving the established first-line therapy in collaboration with National Hospital Organization.

\section{FUTURE DIRECTIONS FOR NKT CELL-MEDIATED CANCER THERAPY USING IPS-DERIVED NKT CELLS}

Although an NKT cell-targeted therapy has been shown to have significant clinical efficacy, only one third of patients are eligible in the case of advanced non-small lung cancer patients; the frequency of NKT cells in the other patients is too low. To overcome this problem, we established in vitro methods for generation of unlimited numbers of functional NKT cells, which then can be transferred into the patients whose endogenous NKT cell numbers are limited.

Induced pluripotent stem (iPS) cells were generated from mature NKT cells using Oct3/4, Sox2, Klf4, and $c-M y c$ genes and then were developed into functional NKT cells in vitro in the presence of IL-7 and Flt3L according to the conventional protocol (42-44). The NKT cells generated in vitro from iPS-NKT cells were functional in the in vivo setting using the experimental model of OVA as an artificial tumor antigen (44). When NKT-KO mice were reconstituted with iPS-derived NKT cells followed by immunization with OVA and $\alpha$-GalCer, we detected a 70 -fold increase in the number of OVA-specific IFN- $\gamma$ producing $\mathrm{CD}^{+} \mathrm{T}$ cells above that seen in the control mice (Figure 2A). Under these conditions, the growth of the OVA-expressing EL4 (EG7) tumor cells was suppressed (Figure 2B). Thus, the iPS-derived NKT cells are able to function in vivo.

Before any clinical application of iPS-derived NKT cells, two immunological issues need to be addressed, one is whether GvHD is induced by NKT cells and the other is whether semiallogeneic NKT cells will work in vivo, because of the clinical use of iPS-derived NKT cells under semi-allogeneic conditions. To address the first question, iPS-derived NKT cells on a B6 background and $\mathrm{B} 6$ or $\mathrm{BALB} / \mathrm{c} \mathrm{CD} 4 \mathrm{~T}$ cells were injected into BALB/c RAG-KO mice. The results were very clear: only B6 CD4T cells, but not iPS-derived B6 NKT cells or BALB/c CD4 T cells, induced GvHD characterized by weight loss, diarrhea, skin disease development, or death after cell transfer. Concerning the second issue of the functional potential of semi-allogeneic NKT cells in vivo (129xB6) F1 NKT cells derived from cloned ES cells established by nuclear transfer of mature NKT cells into unfertilized eggs were injected into B6 NKT-KO mice and analyzed for their adjuvant activity in the OVA model. Significant proliferation of OVA-specific CD8 killer T cells was detected, even though these cells are eliminated in a few days. The ability to generate NKT cells using a simple in vitro culture system offers a powerful approach for the establishment of optimal NKT cell therapy. Our clinical application of the iPS-derived NKT cell therapy program has now been selected as a Center for Clinical Application Research on Specific Disease/Organ (Type B) in the Research Center Network for Realization of Regenerative Medicine, Japan.

\section{FUTURE DIRECTIONS FOR THE NEXT GENERATION OF NKT CELL-TARGETED THERAPY}

For the establishment of the next generation of NKT cell-targeted therapy, we developed artificial adjuvant vector cells to induce both innate and long-term memory CD8T cell responses against cancer. In this system, allogeneic NIH3T3 fibroblasts were used as a vector cell, into which tumor antigen mRNA and CD1d with $\alpha$-GalCer were introduced. In the model experiment, we used OVA mRNA as an artificial tumor antigen together with $\alpha$ GalCer/CD1d to induce the NKT cell-mediated adjuvant effects in vivo in situ (Figure 2C) (22). The allogeneic artificial vector cells were destroyed by the host immune system soon after inoculation and all materials carried by the cells were taken up by the host DCs, which immediately stimulated host NKT cells followed by induction of DC maturation and also by activation of innate NK cells and adaptive OVA-specific CD8 killer T cells. Surprisingly, long-term memory CD8 T cell responses were induced in an antigen-specific manner and persisted even 1 year after the initial single injection and suppressed OVA-expressing tumor cell metastasis (Figures 2D,E) (45). To test if this method could be generalized, we used TRP-2, tyrosinase related protein2 , which is a weak tumor antigen expressed by both mouse and human melanoma cells as the tumor antigen, and successfully suppressed tumor growth in vivo. Therefore, the artificial vector cells should be useful in the future for vaccines against various tumors.

\section{SUMMARY}

Natural killer T cells bridge innate and adaptive immunity, which enhances protective immune responses and also establishes longterm memory responses. Therefore, NKT cells have important therapeutic potential. In support of this notion, clinical trials on NKT cell-targeted therapy have demonstrated clinical safety and significant clinical efficacy in terms of prolonged median overall survival time in lung cancer patients and achieved stable disease status or partial responses in head or neck cancer patients.

The powerful treatment options for the future are to establish iPS cells that can generate unlimited numbers of NKT cells with adjuvant activity in vitro and suppress tumor growth in vivo. The other option is to establish the artificial adjuvant vector cells containing tumor mRNA and $\alpha$-GalCer/CD1d, which have been shown to induce tumor-specific long-term memory CD8T cell responses and to inhibit tumor growth even 1 year after single injection. Thus, these could be therapeutic candidates for the next generation of NKT cell-targeted therapy.

\section{REFERENCES}

1. Taniguchi M, Harada M, Kojo S, Nakayama T, Wakao H. The regulatory role of V $\alpha 14$ NKT cells in innate and acquired immune response. Annu Rev Immunol (2003) 21:483-513. doi:10.1146/annurev.immunol.21.120601.141057 
2. Godfrey DI, MacDonald HR, Kronenberg M, Smyth MJ, Van Kaer L. NKT cells: what's in a name? Nat Rev Immunol (2004) 4(3):231-7. doi:10.1038/nri1309

3. Bendelac A, Savage PB, Teyton L. The biology of NKT cells. Annu Rev Immunol (2007) 25:297-336. doi:10.1146/annurev.immunol.25.022106.141711

4. Imai K, Kanno M, Kimoto H, Shigemoto K, Yamamoto S, Taniguchi M. Sequence and expression of transcripts of the T-cell antigen receptor alpha-chain gene in a functional, antigen-specific suppressor-T-cell hybridoma. Proc Natl Acad Sci U S A (1986) 83(22):8708-12. doi:10.1073/pnas.83.22.8708

5. Koseki H, Imai K, Ichikawa T, Hayata I, Taniguchi M. Predominant use of a particular alpha-chain in suppressor $\mathrm{T}$ cell hybridomas specific for keyhole limpet hemocyanin. Int Immunol (1989) 1(6):557-64. doi:10.1093/intimm/ 1.6.557

6. Koseki H, Imai K, Nakayama F, Sado T, Moriwaki K, Taniguchi M. Homogenous junctional sequence of the V14+ T-cell antigen receptor alpha chain expanded in unprimed mice. Proc Natl Acad Sci U S A (1990) 87(14):5248-52. doi:10.1073/pnas.87.14.5248

7. Cui J, Shin T, Kawano T, Sato H, Kondo E, Toura I, et al. Requirement for $\mathrm{V}<\sigma v \beta>\alpha</ \sigma v \beta>14$ NKT cells in IL-12-mediated rejection of tumors. Science (1997) 278:1623-6. doi:10.1126/science.278.5343.1623

8. Adachi Y, Koseki H, Zijlstra M, Taniguchi M. Positive selection of invariant V alpha 14+ T cells by non-major histocompatibility complex-encoded class I-like molecules expressed on bone marrow-derived cells. Proc Natl Acad Sci U S A (1995) 92(4):1200-4. doi:10.1073/pnas.92.4.1200

9. Zeng Z, Castano AR, Segelke BW, Stura EA, Peterson PA, Wilson IA. Crystal structure of mouse CD1: an MHC-like fold with a large hydrophobic binding groove. Science (1997) 277(5324):339-45. doi:10.1126/science.277.5324.339

10. Kawano T, Cui J, Koezuka Y, Toura I, Kaneko Y, Motoki K, et al. CD1d-restricted and TCR-mediated activation of V $\alpha 14$ NKT cells by glycosylceramides. Science (1997) 278:1626-9. doi:10.1126/science.278.5343.1626

11. Kawano T, Tanaka Y, Shimizu E, Kaneko Y, Kamata N, Sato H, et al. A novel recognition motif of human NKT antigen receptor for a glycolipid ligand. Int Immunol (1999) 11(6):881-7. doi:10.1093/intimm/11.6.881

12. Borg NA, Wun KS, Kjer-Nielsen L, Wilce MC, Pellicci DG, Koh R, et al. CD1dlipid-antigen recognition by the semi-invariant NKT T-cell receptor. Nature (2007) 448(7149):44-9. doi:10.1038/nature05907

13. Spada FM, Koezuka Y, Porcelli SA. CD1d-restricted recognition of synthetic glycolipid antigens by human natural killer T cells. J Exp Med (1998) 188:1529-34. doi:10.1084/jem.188.8.1529

14. Brossay L, Chioda M, Burdin N, Koezuka Y, Casorati G, Dellabona P, et al. CD1dmediated recognition of an $\alpha$-galactosylceramide by natural killer $\mathrm{T}$ Cells is highly conserved through mammalian evolution. J Exp Med (1998) 188:1521-8. doi:10.1084/jem.188.8.1521

15. Brigl M, Brenner MB. CD1: antigen presentation and T cell function. Annu Rev Immunol (2004) 22:817-90. doi:10.1146/annurev.immunol.22.012703.104608

16. Taniguchi M, Seino K, Nakayama T. The NKT cell system: bridging innate and acquired immunity. Nat Immunol (2003) 4(12):1164-5. doi:10.1038/ni12031164

17. Fujii S, Shimizu K, Smith C, Bonifaz L, Steinman RM. Activation of natural killer $\mathrm{T}$ cells by $\alpha$-galactosylceramide rapidly induces the full maturation of dendritic cells in vivo and thereby acts as an adjuvant for combined CD4 and CD8 T cell immunity to a co-administered protein. J Exp Med (2003) 198(2):267-79. doi:10.1084/jem.20030324

18. Hermans IF, Silk JD, Gileadi U, Salio M, Mathew B, Ritter G, et al. NKT cells enhance $\mathrm{CD}^{+}$and $\mathrm{CD}^{+} \mathrm{T}$ cell responses to soluble antigen in vivo through direct interaction with dendritic cells. J Immunol (2003) 171:5140-7.

19. Eberl G, Brawand P, MacDonald HR. Selective bystander proliferation of memory CD4+ and CD8+ T cells upon NK T or T cell activation. J Immunol (2000) 165(8):4305-11.

20. Gumperz JE, Roy C, Makowska A, Lum D, Sugita M, Podrebarac T, et al. Murine CD1d-restricted T cell recognition of cellular lipids. Immunity (2000) 12:211-21. doi:10.1016/S1074-7613(00)80174-0

21. Pardoll DM. The blockade of immune checkpoints in cancer immunotherapy. Nat Rev Cancer (2012) 12(4):252-64. doi:10.1038/nrc3239

22. Fujii S, Goto A, Shimizu K. Antigen mRNA-transfected, allogeneic fibroblasts loaded with NKT-cell ligand confer antitumor immunity. Blood (2009) 113(18):4262-72. doi:10.1182/blood-2008-08-176446

23. Lippitz BE. Cytokine patterns in patients with cancer: a systematic review. Lancet Oncol (2013) 14(6):e218-28. doi:10.1016/S1470-2045(12)70582-X
24. Fujii S, Liu K, Smith C, Bonito AJ, Steinman RM. The linkage of innate to adaptive immunity via maturing dendritic cells in vivo requires CD40 ligation in addition to antigen presentation and CD80/86 costimulation. J Exp Med (2004) 199(12):1607-18. doi:10.1084/jem.20040317

25. Akutsu Y, Nakayama T, Harada M, Kawano T, Motohashi S, Shimizu E, et al. Expansion of lung V alpha 14 NKT cells by administration of alpha-galactosylceramide-pulsed dendritic cells. Jpn J Cancer Res (2002) 93(4):397-403. doi:10.1111/j.1349-7006.2002.tb01270.x

26. Motohashi S, Kobayashi S, Ito T, Magara KK, Mikuni O, Kamada N, et al. Preserved IFN- $\gamma$ production of circulating V $\alpha 24$ NKT cells in primary lung cancer patients. Int J Cancer (2002) 102(2):159-65. doi:10.1002/ijc.10678

27. Toura I, Kawano T, Akutsu Y, Nakayama T, Ochiai T, Taniguchi M. Inhibition of experimental tumor metastasis by dendritic cells pulsed with $\alpha$ galactosylceramide. J Immunol (1999) 163:2387-91.

28. Motohashi S, Nagato K, Kunii N, Yamamoto H, Yamasaki K, Okita K, et al. A phase I-II study of $\alpha$-galactosylceramide-pulsed IL-2/GM-CSF-cultured peripheral blood mononuclear cells in patients with advanced and recurrent non-small cell lung cancer. J Immunol (2009) 182(4):2492-501. doi:10.4049/jimmunol. 0800126

29. Ishikawa E, Motohashi S, Ishikawa A, Ito T, Uchida T, Kaneko T, et al. Dendritic cell maturation by CD11c- T cells and Valpha24+ natural killer T-cell activation by alpha-galactosylceramide. Int J Cancer (2005) 117(2):265-73. doi:10.1002/ijc. 21197

30. Ishikawa A, Motohashi S, Ishikawa E, Fuchida H, Higashino K, Otsuji M, et al. A phase I study of $\alpha$-galactosylceramide (KRN7000)-pulsed dendritic cells in patients with advanced and recurrent non-small cell lung cancer. Clin Cancer Res (2005) 11(5):1910-7. doi:10.1158/1078-0432.CCR-04-1453

31. Motohashi S, Ishikawa A, Ishikawa E, Otsuji M, Iizasa T, Hanaoka H, et al. A phase I study of in vitro expanded natural killer $\mathrm{T}$ cells in patients with advanced and recurrent non-small cell lung cancer. Clin Cancer Res (2006) 12(20 Pt 1):6079-86. doi:10.1158/1078-0432.CCR-06-0114

32. Motohashi S, Okamoto Y, Yoshino I, Nakayama T. Anti-tumor immune responses induced by iNKT cell-based immunotherapy for lung cancer and head and neck cancer. Clin Immunol (2011) 140(2):167-76. doi:10.1016/j.clim.2011. 01.009

33. Motohashi S, Nakayama T. Clinical applications of natural killer T cell-based immunotherapy for cancer. Cancer Sci (2008) 99(4):638-45. doi:10.1111/j.13497006.2008.00730.x

34. Carnaud C, Lee D, Donnars O, Park SH, Beavis A, Koezuka Y, et al. Cutting edge: cross-talk between cells of the innate immune system: NKT cells rapidly activate NK cells. J Immunol (1999) 163(9):4647-50.

35. Smyth MJ, Crowe NY, Pellicci DG, Kyparissoudis K, Kelly JM, Takeda K, et al. Sequential production of interferon- $\gamma$ by NK1.1 ${ }^{+}$T cells and natural killer cells is essential for the antimetastatic effect of $\alpha$-galactosylceramide. Blood (2002) 99:1259-66. doi:10.1182/blood.V99.4.1259

36. Nagato K, Motohashi S, Ishibashi F, Okita K, Yamasaki K, Moriya Y, et al. Accumulation of activated invariant natural killer $\mathrm{T}$ cells in the tumor microenvironment after alpha-galactosylceramide-pulsed antigen presenting cells. J Clin Immunol (2012) 32(5):1071-81. doi:10.1007/s10875-012-9697-9

37. Mountain CF. Revisions in the international system for staging lung cancer. Chest (1997) 111(6):1710-7. doi:10.1378/chest.111.6.1710

38. Socinski MA. The role of chemotherapy in the treatment of unresectable stage III and IV nonsmall cell lung cancer. Respir Care Clin NAm (2003) 9(2):207-36. doi:10.1016/S1078-5337(02)00089-8

39. Shepherd FA, Dancey J, Ramlau R, Mattson K, Gralla R, O'Rourke M, et al. Prospective randomized trial of docetaxel versus best supportive care in patients with non-small-cell lung cancer previously treated with platinum-based chemotherapy. J Clin Oncol (2000) 18(10):2095-103.

40. Huisman C, Smit EF, Giaccone G, Postmus PE. Second-line chemotherapy in relapsing or refractory non-small-cell lung cancer: a review. J Clin Oncol (2000) 18(21):3722-30.

41. Yamasaki K, Horiguchi S, Kurosaki M, Kunii N, Nagato K, Hanaoka H, et al. Induction of NKT cell-specific immune responses in cancer tissues after NKT cell-targeted adoptive immunotherapy. Clin Immunol (2011) 138(3):255-65. doi:10.1016/j.clim.2010.11.014

42. Takahashi K, Yamanaka S. Induction of pluripotent stem cells from mouse embryonic and adult fibroblast cultures by defined factors. Cell (2006) 126(4):663-76. doi:10.1016/j.cell.2006.07.024 
43. Okita K, Ichisaka T, Yamanaka S. Generation of germline-competent induced pluripotent stem cells. Nature (2007) 448(7151):313-7. doi:10.1038/ nature 05934

44. Watarai H, Fujii S, Yamada D, Rybouchkin A, Sakata S, Nagata Y, et al. Murine induced pluripotent stem cells can be derived from and differentiate into natural killer T cells. J Clin Invest (2010) 120(7):2610-8. doi:10.1172/JCI42027

45. Shimizu K, Asakura M, Shinga J, Sato Y, Kitahara S, Hoshino K, et al. Invariant NKT cells induce plasmacytoid dendritic cell (DC) cross-talk with conventional DCs for efficient memory CD8+ T cell induction. J Immunol (2013) 190(11):5609-19. doi:10.4049/jimmunol.1300033

Conflict of Interest Statement: The authors declare that the research was conducted in the absence of any commercial or financial relationships that could be construed as a potential conflict of interest.
Received: 06 November 2013; accepted: 11 November 2013; published online: 02 December 2013.

Citation: Fujii S, Shimizu K, Okamoto Y, Kunii N, Nakayama T, Motohashi S and Taniguchi M (2013) NKT cells as an ideal anti-tumor immunotherapeutic. Front. Immunol. 4:409. doi: 10.3389/fimmu.2013.00409

This article was submitted to Tumor Immunity, a section of the journal Frontiers in Immunology.

Copyright (c) 2013 Fujii, Shimizu, Okamoto, Kunii, Nakayama, Motohashi and Taniguchi. This is an open-access article distributed under the terms of the Creative Commons Attribution License (CC BY). The use, distribution or reproduction in other forums is permitted, provided the original author(s) or licensor are credited and that the original publication in this journal is cited, in accordance with accepted academic practice. No use, distribution or reproduction is permitted which does not comply with these terms. 